\title{
Erratum regarding missing Declaration of Competing Interest statements in previously published articles
}

Declaration of Competing Interest statements were not included in published version of the following articles that appeared in previous issues of Clinical Epidemiology and Global Health. Hence, the authors of the below articles were contacted after publication to request a Declaration of Interest statement:

1. "Role of vitamin a in child health and nutrition" [Clinical Epidemiology and Global Health, 2020; 8 (4): 1039-1042] DOI: https://doi.org/10.1016/j.cegh.2020.03.016

2. "Discriminating malaria and dengue fever in endemic areas: Clinical, biochemical and radiological criteria" [Clinical Epidemiology and Global Health, 2020; 8 (4): 1204-1207] DOI: htt ps://doi.org/10.1016/j.cegh.2020.04.014

3. "Out-of-pocket expenditure for delivery at home and public health facilities in the context of conditional cash transfer and free delivery care programs: An analytical cross-sectional study in South 24 Parganas district, West Bengal, India, 2017" [Clinical Epidemiology and Global Health, 2020; 8 (4): 1395-1401] DOI: https://doi.org/10.1016/j.cegh.2020.06.007

4. "Active bleeding control pilot program in India: Simulation training of the community to stop the bleed and save lives from Road Traffic Injuries" [Clinical Epidemiology and Global Health, 2021; 11: 100729] DOI: https://doi.org/10.1016/j.cegh.20 21.100729

5. "The concordance of triglyceride glucose index (TyG index) and homeostatic model assessment for insulin resistance (Homa-IR) in non-diabetic subjects of adult Indonesian males" [Clinical Epidemiology and Global Health, 2021; 9: 227-230] DOI: htt ps://doi.org/10.1016/j.cegh.2020.09.003

6. "Safe motherhood practices - Knowledge and behaviour among pregnant women in Belagavi, Karnataka. A descriptive study" [Clinical Epidemiology and Global Health, 2021; 12: 100846] DOI: https://doi.org/10.1016/j.cegh.2021.100846

7. "Sociodemographic, behavioral, and environmental factors associated with the incidence of leptospirosis in highlands of Ponorogo Regency, Province of East Java, Indonesia" [Clinical
Epidemiology and Global Health, 2021; 12: 100911] DOI: htt ps://doi.org/10.1016/j.cegh.2021.100911

8. "Impact of socioeconomic and demographic factors for underweight and overweight children in Bangladesh: A polytomous logistic regression model" [Clinical Epidemiology and Global Health, 2020; 8(4): 1348-1355] DOI: https://doi.org/10.1016/j. cegh.2020.05.010

9. "COVID-19 and its impacts: The situation in Niger republic" [Clinical Epidemiology and Global Health, 2021; 11: 100797] DOI: https://doi.org/10.1016/j.cegh.2021.100797

10. "Awareness and attitudes towards common mental health problems of community members in Udupi Taluk, Karnataka: A mixed method study" [Clinical Epidemiology and Global Health, 2021; 10: 100679] DOI: https://doi.org/10.1016/j.cegh.2020.100679

11. "Spatial mapping of COVID-19 for Indian states using Principal Component Analysis" [Clinical Epidemiology and Global Health, 2021; 10: 100690] DOI: https://doi.org/10.1016/j.cegh.2020 .100690

12. "Effectiveness of voice stimulus on the level of consciousness, physiological parameters and behavioural responses in comatose patients - A feasibility study" [Clinical Epidemiology and Global Health, 2021; 9: 150-156] DOI: https://doi.org/10.1016/j.cegh .2020.08.006

13. "Study on age of menarche between generations and the factors associated with it" [Clinical Epidemiology and Global Health, 2021; 11: 100758] DOI: https://doi.org/10.1016/j.cegh.20 21.100758

14. "Association between prolonged use of smartphone and the incidence of dry eye among junior high school students" [Clinical Epidemiology and Global Health, 2021; 11: 100761] DOI: htt ps://doi.org/10.1016/j.cegh.2021.100761

15. "Characterization of the patellar tendon reflex response using an indigenously developed system and implementation of a strategic protocol to assess its clinical usefulness" [Clinical Epidemiology and Global Health, 2021; 12: 100881] DOI: https://doi.org/10 .1016/j.cegh.2021.100881

DOIs of original article: https://doi.org/10.1016/j.cegh.2020.03.016, https://doi.org/10.1016/j.cegh.2020.100690, https://doi.org/10.1016/j.cegh.2021. 100761, https://doi.org/10.1016/j.cegh.2021.100911, https://doi.org/10.1016/j.cegh.2020.05.010, https://doi.org/10.1016/j.cegh.2021.100729, https://doi.org/ 10.1016/j.cegh.2020.09.003, https://doi.org/10.1016/j.cegh.2021.100797, https://doi.org/10.1016/j.cegh.2020.08.006, https://doi.org/10.1016/j.cegh.2020.04. 014, https://doi.org/10.1016/j.cegh.2020.06.007, https://doi.org/10.1016/j.cegh.2021.100758, https://doi.org/10.1016/j.cegh.2021.100846, https://doi.org/10. 1016/j.cegh.2020.100679, https://doi.org/10.1016/j.cegh.2021.100881.

https://doi.org/10.1016/j.cegh.2022.100990

Available online 4 February 2022

2213-3984/C 2022 The Author(s). Published by Elsevier B.V. on behalf of INDIACLEN. All rights reserved. 